\title{
Taktik Oyun Yaklaşımıyla Yapılandırılmış Voleybol Eğitimi Sonrası Sporcuların Oyun Performanslarının Değerlendirilmesi
}

\author{
Evaluation of Volleyball Players' Game Performance After Training Designed With \\ Tactical Game Approach
}

\author{
${ }^{1}$ Burak GÜNEŞ \\ ${ }^{2}$ A. Dilşad MİRZEOĞLU \\ ${ }^{3}$ Hakan GÖVELİ \\ ${ }^{4}$ Ezgi TULAY
}

${ }^{1}$ Nevşehir Hacı Bektaş Veli Üniversitesi, Spor Bilimleri ve Teknolojisi Yüksekokulu

${ }^{2}$ Sakarya Uygulamalı Bilimler Üniversitesi, Spor Bilimleri Fakültesi

${ }^{3}$ MEB, Betül Can Anadolu Lisesi

${ }^{4}$ Kırıkkale Üniversitesi, Sağl1k Bilimleri Enstitüsü, Hareket ve Antrenman Bilimleri Bilim Dalı

\section{Yazışma Adresi \\ Corresponding Address:}

Dr. Öğretim Üyesi Burak GÜNEŞ

ORCID: 0000-0002-6571-646X

Nevşehir Hacı Bektaş Veli Üniversitesi, Spor Bilimleri ve Teknolojisi Yüksekokulu

E-posta: gunesburak82@gmail.com

\section{öz}

$\mathrm{Bu}$ araştırmanın amacı taktik oyun yaklaşımı kullanılarak yürütülen voleybol eğitimi sonrası sporcuların voleybol oyun performanslarını incelemektir. Araştırma ön test- son test kontrol grupsuz yarı-deneysel bir çalışma olup, araştırmanın çalışma grubunu spor kulübüne devam eden $15 \mathrm{k} 1 \mathrm{z}$ sporcu oluşturmaktadır. Araştırmada sporcuların oyun performanslarını ve oyun performans bileşenlerini değerlendirmek için Oyun Performansı Değerlendirme Ölçeği (OPDÖ) kullanılmıştır. Araştırmada elde edilen verileri çözümlemek için Wilcoxon işaretli sıralar ve Mann Whitney U testleri kullanılmıştır. Araştırma bulgularına göre sporcuların oyun performansı ve oyun performansını meydana getiren bileşenlerde (karar verme, beceri uygulama, ayarlama ve katılım) ön test-son test puanları arasında son test lehine anlamlı fark bulunmuştur. Araştırma sonuçlarına göre taktik oyun yaklaşımının oyun performansı ve bileşenlerinin gelişimi üzerinde olumlu yönde etkili olduğu söylenebilir. Taktik oyun yaklaşımı özellikle voleybola yeni başlayan sporcularda taktiklerin ögretilmesi için bir alternatif olarak düşünülebilir.

Anahtar Kelimeler: Oyun, Taktik oyun yaklaşımı, Voleybol, Performans

\section{ABSTRACT}

The aim of this study is to evaluate the game performance of the players after volleyball training, which is carried out by using tactical game approach. The study was a semi-experimental study with pre-test and post-test and noncontrol group. The study group consists of 15 female athletes attending a sports club. Wilcoxon signed rank and Mann Whitney U tests were used to analyze the data. The Game Performance Assessment Instrument (GPAI) was used to evaluate the game performance and game performance components of the athletes. The results showed that, there was a statistically significant difference between the pre-test and post-test scores of the game performance and game performance components (decision making, skill execution, adjustment and participation) of athletes. According to the research results, it can be said that tactical game approach has a positive effect on the development of game performance and game performance components. The Tactical Game Approach can be considered as an alternative to the teaching of tactics, especially for beginners in volleyball.

Key Words: Game, Tactical game approach, Voleyball, Performance 


\section{GíRIŞ}

Voleybol eğitiminin nihai amacı sporcuların voleybol oynamasını sağlayabilmektir. Oyun manşet pas, parmak pas, servis, smaç, blok ve plonjon temel becerilerini içermekte ve yapısı gereği bu becerilerin oyuncular tarafından birbirine bağlı olarak uygulanmasını gerektirmektedir. Örneğin voleybolda etkili bir hücum vuruşu olan smacın başarısını, kendisinden önce yapılacak olan becerilerin mükemmelliği belirlemektedir. Şöyle ki; etkili hücumun yapılabilmesi, hücum vuruşu yapacak oyuncuya topu istenilen noktaya gönderebilmek için en uygun teknik olan parmak pas ile sağlanabilir. Etkili bir parmak pası ise savunma oyuncusu tarafından alınan manşet pasın kalitesi belirlemektedir. Başka bir ifadeyle oyun kurucu (pasör) ve hücum oyuncularının performanslarını en iyi şekilde sergileyebilmeleri için manşet pasın fileden en uygun yükseklikte ve uzaklıkta olması gerekmektedir (Orkunoğlu, 1988). Ancak beklendik oyun performansını elde etmek, oyunda kullanılan temel becerilerin uygulanmasının yanında, oyuncuların bazı kararlar almasını ve ayarlamalar yapmasını da gerektirir. Örneğin servis karşılayacak bir sporcunun servisin düşeceği yeri top gelirken farkına varıp önceden öne-geriye-yana doğru hareket etmesi veya manşetten gelen topun hangi pas ile hücum oyuncusuna atılacağının seçilmesi ya da hücum vuruşu yapacak olan oyuncunun hücum için gerekli hazırlıkları yapması bu gibi ayarlama ve kararlardandır. İşte oyun içerisinde tüm bu ayarlama ve kararların alınıp uygulamaya dökülmesi taktik (Holt ve diğerleri, 2002) olarak tanımlanmaktadır.

Genellikle spor eğitimcileri (beden eğitimi öğretmenleri, antrenörler) sporculara/öğrencilere önce temel becerileri öğretip, daha sonra bu becerileri oyunda kullanmaya yönelik bir öğretim yaklaşımı izlemektedir. Bu şekilde yapılandırılan eğitim uygulamalarının ise sporcuların sıkılmasına sebep olduğu öne sürülmektedir ( Mitchell ve diğerleri, 2013:19). Ayrıca beceriler taktiksel bağlamın dışında izole bir şekilde öğretildiği için sporcular teknik ve taktiğin oyuna transfer edilmesinde sorunlar yaşamaktadır. Sporcular oyununu oynamak için gerekli becerileri (manşet pas, parmak pas, servis) öğrenmiş olsalar bile oyun içerisinde bu becerilerin ne zaman, nasıl kullanılacağı ile ilgili sorunlar yaşayabilmektedir (Light, 2005:17; Pigot,1982). Bu bağlamda Bunker ve Thorpe 1982 y1lında bu sorunu ortadan kaldırmak için oyunları anlamayı öğrenme yaklaşımını öne sürmüşlerdir. Yaklaşım, literatürde geniş yankı uyandırmış ve birçok türevi ortaya çıkmıştır. Bu yaklaşımları şu şekilde sıralayabiliriz; Oyunları Anlamayı Öğrenme Modeli (Teaching Games for Understanding - TGFU, Bunker, Thorpe ve Almond, 1986), Taktiksel Oyun Yaklaşımı (Tactical Games Approach; Mitchell, Oslin ve Griffin, 2006), Oyunu Hissetme (Game Sense; Den Duyn, 1997; Light, 2006), Taktiksel Oyun Modeli (Tactical Games Model; Metzler, 2005), Oyun Uygulama/Alıştırma (Play Practice; Launder 2001; Launder ve Piltz, 2013), Taktiksel-Karar Öğrenme Modeli (Tactical-decision Learning Model; Gréhaigne, Wallian ve Godbout, 2005), Top-Okul Kavramı (Ball-School Concept, Memmert ve Roth, 2007), Hücum Oyunları Yarış Modeli (Invasion Games Competence Model, Tallir, Lenior, Valcke ve Musch, 2007), Oyunlar Kavramı Yaklaşımı (Games Concept Approach; McNeill ve diğerleri, 2008) (Almond, 2015).

Stolz ve Pill (2014:37) ortaya çıkan bu yaklaşımlar ile ilgili olarak; yaklaşımların aralarında ince farklılıklar olduğunu öne sürerek temelde taktiksel yapının öncelikle öğretilmesi gerektiğine vurgu yapmıştır. Bu yaklaşımlardan biri olan taktik oyun yaklaşımı (TOYA) son zamanlarda oyunların öğretilmesinde sıklıkla kullanılmaktadır. TOYA'da orijinal oyunları öğrenmeyi anlama modelinin (Bunker ve Thorpe,1982) sunduğu teknikten önce taktik öğretimi önermesi değişmemiştir. Ancak taktik oyun yaklaşımı pedagojisi için önemli olan oyun performansı değerlendirme ölçeği (OPDÖ) olarak bilinen bir değerlendirme aracı eklenmiştir. OPDÖ taktiksel karar vermeyi, topsuz hareketleri okumayı ve cevap vermeyi, top ile beraber reaksiyon vermeyi ve daha sonra oyunla ilişkili bir pozisyona geri gelmeyi kodlama olarak tanımlanmaktadır (Hopper, 2003). TOYA'da taktikten beceriye doğru bir öğretim sırası izlenmektedir. Eğitim modifiye 
bir oyun ile başlamakta ve sırasıyla taktiksel sorgulama, beceri pratiği ve son olarak oyun aşamalarıla ile bitirilmektedir. Bu sayede katılımcıların becerileri oyun içerisinde niçin kullanıldıklarını kavradıkları için oyunu daha iyi oynadıkları öne sürülmektedir.

Oyun temelli yaklaşımlar literatürde bir paradigma olarak ortaya çıktığından beri (Bunker ve Thorpe, 1982) sportif oyun öğretiminde oyun temelli yaklaşımların kullanılmasıyla ilgili olarak dünyada bir çok çalışma yapılmıştır. Bu çalışmalar, oyunların taktiksel yapısındaki benzerlikler-farklılıklar ve araştırılan grupların seviyesindeki farklılıklar (yaş, cinsiyet, beceri seviyesi, taktiksel karmaşıklık seviyesi), araştırmacıları oyun performansının farklı boyutlarını incelemeye yöneltmiş̧ir. Ayrıca spor eğitiminin birçok gelişim alanını içermesi (bilişsel, duyuşsal, psikomotor) araştırmaların farklı davranış alanlarında çeşitlilik göstermesine neden olmuştur.

Konuyla ilgili olarak çeşitli branşlarda yapılan bazı çalışmalarda oyun temelli yaklaşımların oyuna katılımı arttırdığı ( Harvey, 2004; Mitchell ve diğerleri,1995), karar vermede daha fazla gelişmiş bir grup meydana getirdiği (Alarcón ve diğerleri, 2009; Broek ve diğerleri, 2011; French ve diğerleri 1996; Gray ve Sproule 2011; Güneş, 2017; Harvey 2004; Mitchell ve diğerleri,1995; Şahin 2007; Turner, 1996; Turner ve Martinek,1999; Žuffová ve Zapletalová, 2015), öğrencilerin derslerden daha fazla keyif aldıkları (Cruz, 2004; Turner;1996; Wallhead ve Deglan 2004), katılımc1 motivasyonunu arttırdığı (Jones ve diğerleri, 2010; Wallhead ve Deglan,2004) benzer taktiksel yapıya sahip oyunları oynayan öğrencilerin öğrenmiş oldukları taktiksel bilgiyi diğer oyuna transfer edebildikleri (Harrison ve diğerleri,2004; Holt ve diğerleri, 2006; Jones ve Farrow 1999; Martin, 2004; Mitchell ve Oslin 1999), beceri uygulama (Alison ve Thorpe,1997; Dinç, Altay ve Çelenk, 2008; French ve diğerleri 1996; Harrison ve diğerleri,2004; Harvey, 2004; Mitchell ve diğerleri,1995; Şahin 2007;Turner ve Martinek,1999; Tuzcuoğlu,2006; Žuffová ve Zapletalová, 2015) ve ayarlama (Harvey, 2004) bileşenini geliştirdiği, destekleme bileşenine katkı sağladığı (Alarcón ve diğerleri,2009;Güneş, 2017; Şahin 2007) ve oyun performansını geliştirdiği (Bohler,2009; Güneş, 2017; Lee ve Ward 2009; Şahin 2007; Tuzcuoğlu,2006) görülmektedir. Ayrıca voleybol branşı ile ilgili olarak; Jones ve Farrow (1999) voleybol eğitiminin badmintonda karar verme becerisini geliştirdiğini; Harrisson ve diğerleri (2004) voleybol oyun denemelerinin videolarını kodlayarak üniversite öğrencileri üzerinde yaptıkları çalışmada, oyun oynamada iyileşme sağlandığını; Broek (2011) taktiksel farkındalık testi kullanarak üniversite öğrencileri üzerinde yaptığı çalışmada taktiksel farkındalıkta artış meydana geldiğini; Henninger ve diğerleri (2006) voleybol dersini seçen öğrencilerden nitel veri elde ederek yaptığ1 çalışmada, öğretmenlerin taktik kararları geliştirmek için uygun ortam sağlamaları gerektiği, öğrencilerin ise beden eğitimi ortamına getirmiş oldukları bilgileri taktiksel bilgiyle birleştirmekte güçlük çektiklerini; Bohler (2009) ise 6. sınıf beden eğitimi dersi öğrencileri ve öğretmenlerinin niteliksel analizi sonucunda TOYA ile taktiksel bilginin geliştirilebileceğini ortaya koymuştur.

Voleybol oyununun teknik bir branş olması, oyunun oynanabilmesi için bazı temel tekniklerin bilinmesinin gerekli olması voleybol eğitimcilerini taktik anlayıştan yoksun izole çalışmalara itmektedir. Bu durum özellikle voleybola yeni başlayanlar için sıkııı bir durum haline gelebilmektedir. Ayrıca tekniklerin taktik bağlamın dışında izole bir şekilde öğretilmesi tekniklerin oyuna transfer edilmesinde sorunlar yaşatabilmektedir. Taktik Oyun Yaklaşımı yapısı gereği öğrencilerin/ sporcuların oyun oynayarak teknik ve taktikleri birlikte öğrendikleri bir öğretim durumu ortaya koymaktadır. Ancak dünyada voleybol branşıyla ilgili yapılmış çalışma oldukça azdır. Ülkemizde ise voleybol branşıyla ilgili Dinç ve diğerlerinin (2008) yaptığ çalışma dışında taktik oyun yaklaşımı ile ilgili bir çalışmaya rastlanmamıştır. Bu durum voleybola yeni başlayan sporcularda oyun performansının ve oyun performansını meydana getiren bileşenlerin analiz 
edilmesini ve TOYA eğitimi sonrasında oyun performansı bileşenlerinde ne gibi değişikliklerin meydana geldiğinin ortaya konulması ihtiyacını doğurmaktadır. Ayrıca beden eğitimi öğretmenleri ve antrenörlere oyun öğretimi yaklaşımları hakkında bilinçli seçimler yapmaları konusunda bilgi sağlamak için oyun temelli yaklaşımları inceleyen çalışmalara ihtiyaç olduğu görülmektedir. Bu nedenle yapılan çalışmanın ülkemizde Taktik oyun yaklaşımıyla ile ilgili yapılacak olan çalışmalara ışık tutması ve literatüre katkıda bulunması beklenmektedir. Bu noktadan hareketle gerçekleştirilen çalışmanın amacı, voleybola yeni başlayan sporcularda TOYA kullanılarak yürütülen voleybol eğitiminin, voleybol oyun performansını tanımlayan karar verme, beceri uygulama, ayarlama bileşenlerini ve bu bileşenlere bağlı olarak ortaya çıkan sporcuların oyuna katılım ve oyun performanslarını değerlendirmektir.

\section{YÖNTEM}

Araştırma yarı-deneysel bir çalışma olup, deneme modellerinden ön-son test kontrol grupsuz model kullanılarak tasarlanmıştır. Araştırmanın bağımsız değiş̧kenini taktik oyun yaklaşımı ile hazırlanmış voleybol eğitim programı, bağımlı değişkenlerini ise; sporcuların karar verme, beceri uygulama, ayarlama, oyuna katılım ve oyun performansı indeksleri oluşturmaktadır. Araştırma için Nevşehir Hacı Bektaş Veli Üniversitesi Girişimsel Olmayan Klinik Araştırmalar Etik Kurulundan, (27.09.2018 tarih ve 2018.11.131 sayılı karar ) etik kurul izni alınmıştır. Ayrıca çalışma "Helsinki Bildirgesine uygun olarak ve katılımcılardan (uygulamaya katılan katılımcıların aileleri) imzalı onam formu alınarak gerçekleştirilmiş ve tüm katılımcıların araştırmaya kendi rızası ile katılmaları sağlanmıştır.

Araştırma Grubu: Araştırmaya Ankara İli Çankaya İlçesinde bulunan bir kulübün voleybol alt yapısına devam eden, yaş ortalaması $12.13 \pm 0.83$ (min-max=11-13) olan ve bir y1llık spor deneyime sahip 15 kız sporcu katılmıştır. Benzer yaş ve beceri düzeyinde yeterli sporcunun olmaması nedeniyle çalışmaya kontrol grubu dâhil edilmemiştir. Katılımcılardan araştırma süresince voleybol çalışma programına uymaları ve program dışında herhangi bir voleybol etkinliğine katılmamaları istenmiştir. Katılımcılardan herhangi bir programa katılmadıkları konusunda sözlü olarak bilgi alınmış ve tüm katılımcılar program dışı voleybol etkinliğine katılmadıklarını beyan etmiş̧lerdir.

Veri Toplama Araçları: Çalışmada veri toplamak için Oslin, Mitchell ve Griffin (1998) tarafından geliştirilen oyun performansı değerlendirme ölçeği (OPDÖ) ön test-son test olarak uygulanmıştır.

Oyun performansı değerlendirme ölçeği (OPDÖ): Çalışma gurubunun oyun performanslarını değerlendirmek için Oslin ve diğerleri (1998) tarafından geliştirilen "Oyun Performansı Değerlendirme Ölçeği” kullanılmıştır. Bu çalışmada oyun performansı değerlendirme ölçeği içerisinden karar verme, beceri uygulama ve ayarlama bileşenleri seçilerek voleybola uyarlanmıştır. Seçilmiş olan bileşenler için her bir oyuncu için tek tek karar verme indeksi, beceri uygulama indeksi ve ayarlama indeksi oluşturulmuştur. Daha sonra oluşturulmuş olan indeksler üzerinden her bir oyuncunun oyuna katılımı ve oyun performansı hesaplanmıştır.

Her bir oyuncunun bireysel indekslerinin hesaplanması Tablo 1'de gösterilmiştir (Metzler, 2005: 426). 
Tablo 1. Oyuncuların bireysel indekslerinin hesaplanması

\begin{tabular}{|c|c|}
\hline İndeks & Hesaplama \\
\hline Karar Verme Endeksi (KVİ) & $\begin{array}{l}\text { Uygun Kararların Sayıs1 / Uygun Olmayan Kararların } \\
\text { Sayıs1 }\end{array}$ \\
\hline Beceri Uygulama İndeksi (BUİ) & $\begin{array}{l}\text { Etkin Beceri Uygulama Sayıs1/Etkili Olmayan Beceri } \\
\text { Uygulama Sayısı }\end{array}$ \\
\hline Ayarlama İndeksi (Aİ) & $\begin{array}{l}\text { Uygun Ayarlama Hareket Sayısı /Uygun Olmayan } \\
\text { Ayarlama Hareket Sayısı }\end{array}$ \\
\hline Oyun Performans1 & $\begin{array}{l}\text { (Karar Verme İndeksi + Beceri Uygulama İndeksi + } \\
\text { Ayarlama İndeksi) / } 3\end{array}$ \\
\hline Oyun Katılım & $\begin{array}{l}\text { Uygun Kararların Sayıs1 + Uygun Olmayan } \\
\text { Kararların Sayıs1 + Etkin Beceri Uygulama Sayısı + } \\
\text { Verimsiz Beceri Uygulama Sayısı + Uygun } \\
\text { Ayarlama Hareketi Sayısı }\end{array}$ \\
\hline
\end{tabular}

Voleybol için hazırlanmış oyun performansı değerlendirme ölçeğine ait örnek kodlama ve hesaplama Tablo 2'de verilmiştir (Mitchell ve diğerleri, 2013:121).

Tablo 2. Oyun performansı değerlendirme ölçeğine ait örnek kodlama

\begin{tabular}{ccccccc}
\hline & \multicolumn{2}{c}{ Karar Verme } & \multicolumn{2}{c}{ Beceri Uygulama } & \multicolumn{2}{c}{ Ayarlama } \\
\hline & Uygun & Uygun & Uygun & Uygun & Uygun & Uygun \\
& & Değil & & Değil & & Değil \\
\hline Sporcu A & XXXXXX & $\mathrm{X}$ & XXXXXX & $\mathrm{X}$ & $\mathrm{XXXXXX}$ & XXXX \\
\hline
\end{tabular}

Değerlendirme sonuçları şu şekildedir;

Oyuna katılım: $7+7+6=20$

Karar verme indeksi: $6 / 1=6$

Beceri uygulama indeksi: $6 / 1=6$

Ayarlama indeksi: 6/4 =1,5

Oyun performans1: $(6+6+1,5) / 3=4,5$

Karar verme kategorisine, servisin hangi beceriler kullanılarak karşılanacağı ve karşılanan servis sonrasında topun hangi bölgeye atılacağ1, oyun kuracak olan oyuncunun (pasör) topu hangi beceriyi kullanarak oyun kuracağ1 ve hangi oyuncuya pas kaldıracağı, hücum yapacak olan oyuncunun hangi beceriyi kullanacağı ve topu hangi bölgeye göndereceği vb. kriterler alınmıştır. Beceri uygulaması kategorisi, parmak pas, manşet pas, servis, hücum vuruşu becerilerinden oluşturulmuştur. Oyuncu, oyun kuralları doğrultusunda nizami yaptığı her beceride olumlu (etkili), topu taşıdığı, fırlattığı, dışarı (out) attığı her pozisyonda olumsuz (etkili değil) puan almıştır. Ayarlama kategorisi ise; oyuncunun topu takip etmesi, pasörün servis karşılandıktan sonra oyun kurmak için hazırlanması ve topa hareket etmesi, smaç vuracak oyuncunun top pasöre geldiğinde smaç vurmak için açılması, servis karşılama sistemine göre oyun alanında uygun yerleşim yapması vb. kriterlerden oluşturulmuştur (Çelen, 2012; Pritchard ve diğerleri, 2008).

Oyun performanslarının belirlenmesi için, çalışmaya katılan sporcuların maçlar esnasındaki uygulamaları hem ön testlerde hem de son testlerde 12 dakika boyunca kameraya çekilerek kayıt altına alınmış, yapılan kayıtlar voleybol alanında uzman iki kişi (1. uzman: Voleybol 3. kademe antrenörlük belgesine sahip, 2. uzman: 1. kademe antrenörlük 
belgesine sahip, altyapı voleybol öğretiminde 15 yıllık antrenörlük ve 15 yıl beden eğitimi öğretmenliği deneyimi bulunmaktadır) tarafindan, "karar verme", "beceri uygulaması" ve "ayarlama” bileşenleri göz önünde bulundurularak bağımsız olarak izlenmiş ve çeteleme yöntemi kullanılarak kodlanmıştır. Her oyuncu için bireysel indeksler çıkarılmış ve gerekli formüller kullanılarak, her oyuncunun bireysel karar verme indeksi, beceri uygulaması indeksi, ayarlama indeksi, oyun performansı indeksi ve oyuna katılım indeksi belirlenmiştir. Gözlemciler arası güvenirliği hesaplamak için, gözlemcilerin karar verme, beceri uygulama, ayarlama ön test ve son test puanları arasındaki tutarlılığa (Tablo 3. ve Tablo 4.) Mann Whitney U testi ile bakılmış, gözlemcilerin öğrencilere verdikleri puanlar arasında istatistiksel olarak anlamlı bir fark bulunmamıştır $(\mathrm{p}>0.05)$.

Tablo 3. Gözlemcilerin ön test puanları arsındaki tutarlılık

\begin{tabular}{lccccccc}
\hline Beceriler & Gözlemci & $\mathbf{N}$ & $\begin{array}{c}\text { Sira } \\
\text { Ortalaması }\end{array}$ & $\begin{array}{c}\text { Sıra } \\
\text { Toplamı }\end{array}$ & $\mathbf{z}$ & $\mathbf{U}$ & $\mathbf{p}$ \\
\hline Karar & 1 & 15 & 14.83 & 222.50 & -0.417 & 102.500 & 0.683 \\
verme & 2 & 15 & 16.17 & 242.50 & & & \\
Beceri & 1 & 15 & 15.43 & 231.50 & -0.042 & 111.500 & 0.967 \\
uygulama & 2 & 15 & 15.57 & 233.50 & & & \\
Ayarlama & 1 & 15 & 14.60 & 219.00 & -0.676 & 99.500 & 0.595 \\
& 2 & 15 & 16.40 & 246.00 & & & \\
\hline
\end{tabular}

Tablo 4. Gözlemcilerin son test puanlarındaki tutarlılık

\begin{tabular}{lccccccc}
\hline Beceriler & Gözlemci & $\mathbf{N}$ & $\begin{array}{c}\text { Sira } \\
\text { Ortalaması }\end{array}$ & $\begin{array}{c}\text { Sıra } \\
\text { Toplamı }\end{array}$ & $\mathbf{z}$ & $\mathbf{U}$ & $\mathbf{p}$ \\
\hline Karar & 1 & 15 & 15.70 & 235.50 & -0.125 & 109.500 & 0.902 \\
verme & 2 & 15 & 15.30 & 229.50 & & & \\
Beceri & 1 & 15 & 15.27 & 229.00 & -0.146 & 109.500 & 0.902 \\
uygulama & 2 & 15 & 15.73 & 236.00 & & & \\
Ayarlama & 1 & 15 & 16.50 & 247.50 & -0.169 & 108.500 & 0.870 \\
& 2 & 15 & 14.50 & 217.50 & & &
\end{tabular}

Verilerin Toplanması: Çalışmada veri toplamak için Oslin, Mitchell ve Griffin (1998) tarafından geliştirilen oyun performansı değerlendirme ölçeği (OPDÖ) ön test-son test olarak uygulanmıştır. Veriler nicel olarak elde edilmiştir. Sporculara manşet pas, parmak pas ve alttan servis ve hücum vuruşu (sıçrayarak parmak pas veya fileden aşağıya doğru giden top atma) becerilerini içeren 10 adet eğitim 5 hafta süresince uygulanmıştır. Her bir eğitim 90 dakika olmak üzere haftada 2 gün uygulanmıştır. Uygulama yapan araştırmacı, bu modeli daha önce doktora tezinde farklı bir spor branşında uygulaması nedeniyle konu ile ilgili yeterli deneyime sahiptir.

Çalışmada kullanılan TOYA eğitim programı Mitchell ve diğerlerinin (2013) geliştirmiş oldukları voleybol modülünden uyarlanarak hazırlanmıştır. Hazırlanan program beden eğitimi ve spor öğretimi alanında bir uzman tarafından okunmuş ve gelen görüşler doğrultusunda gerekli düzeltme ve düzenlemeler yapılmıştır. Eğitime başlamadan önce uygulama yapacak araştırmacı tarafından çalışma gurubuna taktik oyun yaklaşımı ile ilgili genel bilgiler verilmiş ve eğitimin nasıl yürütüleceği konusunda açıklamalar yapılmıştır. Taktik oyun yaklaşımı eğitimi uyarlanmış oyun, soru 
cevap oturumu, beceri pratiği, oyuna dönüş aşamalarını içeren dört bölümden oluşmuş bir planlamayla işlenerek, sporcuların voleybol becerilerini oyun içerisinde nerede ve niçin kullanacaklarını, taktik açıdan neler yapmaları gerektiğini ve maç sırasında sonuca nasıl ulaşabileceklerini görmelerini sağlayan etkinliklere yer verilmiştir. Her bir çalışmada sporcular bir voleybol antrenörü tarafından ısınma ve açma germe egzersizlerini tamamlamış olarak eğitim alanına alınmışlardır. Isınma ve açma germe egzersizleri tamamlandıktan sonra TOYA modeli ile eğitime başlanmıştır. Sporcular modelin formatı gereği olarak öncelikle ilk oyuna alınmıştır. İlk oyunda sporcuların oyunu deneyimlemeleri sağlanmış ve daha sonra taktiksel sorgulamaya geçilmiştir. Taktiksel sorgulama aşamasında oyunu dondurma ve yeniden yapılandırma stratejilerinden yararlanılmıştır. Örneğin manşetin oyun kurucuya (pasör) yüksek bir şekilde alınmasına odaklanılan bir antrenmanda oyun eğitmen tarafından izlenmiş, topun pasöre alınmadığı durumda ve dolayısıyla etkisiz bir hücum organizasyonunda oyun antrenör tarafından dondurulmuş ve taktiksel sorgulamaya gidilmiştir. Antrenör taktiksel sorgulamada antrenmanın odağını gerçekleştirmeye yönelik sorular sormuştur. Örneğin; Soru 1: Niçin etkili bir hücum yapamadınız? Cevap 1: Çünkü takım arkadaşım topu smaç vurabileceğim şekilde kaldıramadı. Soru 2: Peki neden kaldıramadı? Cevap 2: Çünkü topu istediği gibi alamadı. Soru 3: O halde biz topu nasıl göndermeliyiz? Cevap 3: Oyun kurucuya yüksek bir şekilde. Soru 4: Ne kadar yüksek? Cevap 4: Pasörün parmak pas yapabileceği yükseklikte, yaklaşık 1 metre üstüne. Uygun cevap alındıktan sonra oyun antrenör tarafından tekrar yapılandırılmıştır. İlk oyun ve taktiksel sorgulama süreci yaklaşık 30 dakika sürmüştür. Beceri uygulama aşamasında ise sporculara o günkü taktiksel problemin çözümünde kullanılan beceriler ile ilgili alıştırmalar yaptırılmıştır. Örneğin sporculardan biri file önüne alınarak diğer arkadaşına top atması istenmiş ve atılan topun sporcu tarafından tekrar topu atan arkadaşına tıpkı pasöre top atar gibi manşet ile göndermesi istenmiştir. Beceri pratiği aşamasındaki çalışmalar yaklaşık 30 dakika süresince çeşitli alıştırmalar ile sürdürülmüştür. Son olarak sporcular son oyuna alınmış. Burada daha önceki aşamalarda (ilk oyun-taktiksel sorgulama-beceri pratiği) elde etmiş oldukları taktiksel farkındalık ve tekniği son oyunda deneyimleme şansları verilmiştir. Son oyun 30 dakika sürmüştür. TOYA Eğitim programı aşağıda sunulmuştur.

Tablo 5. TOYA eğitim programı.

\begin{tabular}{|c|c|c|c|c|}
\hline Çalıșmalar & Taktiksel Problemler & Ders Odağı & Beceri & Uygulamalar \\
\hline 1. Çalışma & Hücumda oyun kurma & Manşet pas & Manşet & \multirow{3}{*}{ *Isinma } \\
\hline 2. Çalışma & Hücumda oyun kurma & Pasöre uygun pas & Manşet & \\
\hline 3. Çalıșma & Hücumda oyun kurma & Pasöre uygun pas & Manșet & \\
\hline 4. Çalışma & Hücumda oyun kurma & Parmak pas & Parmak pas & \multirow{3}{*}{$\begin{array}{l}\text { *Taktiksel } \\
\text { Sorgulama }\end{array}$} \\
\hline 5. Çalışma & Hücumda oyun kurma & Smaçöre uygun pas & $\begin{array}{l}\text { Parmak pas, } \\
\text { Manset pas }\end{array}$ & \\
\hline 6. Çalışma & Hücumda oyun kurma & Smaçöre uygun pas & $\begin{array}{l}\text { Parmak pas, } \\
\text { Manșet pas }\end{array}$ & \\
\hline 7. Çalışma & Sayı kazanma & Smaç vuruşuna geçiş & $\begin{array}{l}\text { Fileden aşağıya } \\
\text { doğru giden top } \\
\text { atma, Smaç }\end{array}$ & \multirow{4}{*}{$\begin{array}{l}\text { *Beceri } \\
\text { Pratiği } \\
* 3 \times 3 \text { Oyun }\end{array}$} \\
\hline 8. Çalışma & Sayı kazanma & Smaç vuruşuna geçiş & $\begin{array}{l}\text { Fileden aşağıya } \\
\text { doğru giden top } \\
\text { atma, Smaç }\end{array}$ & \\
\hline 9. Çalışma & Sayı kazanma & Alttan servis & $\begin{array}{l}\text { Alttan servis, } \\
\text { Diğer beceriler }\end{array}$ & \\
\hline 10. Çalışma & Sayı kazanma & Alttan servis & $\begin{array}{l}\text { Alttan servis, } \\
\text { Diğer beceriler }\end{array}$ & \\
\hline
\end{tabular}

Verilerin Analizi: Araştırmada verilerin analizinde kullanılacak istatistiksel yöntemlere karar vermek için verilerin normal dağılıp dağılmadığına Shapiro-Wilks, varyansların homojenliğine ise Levene testi ile bakılmıştır. Yapılan 
analizler sonucunda bazı verilerin normal dağılım gösterdiği bazılarının ise normal dağılım göstermediği; karar verme ön test $(\mathrm{z}=0.031, \mathrm{p}<0.05)$, beceri uygulama öntest $(\mathrm{z}=0.00, \mathrm{p}<0.05)$, ayarlama ön test $(\mathrm{z}=0.00, \mathrm{p}<0.05)$, kat 1 lim ön test $(\mathrm{z}=0.711, \mathrm{p}>0.05)$, oyun performans1 ön test $(\mathrm{z}=0.038, \mathrm{p}<0.05)$, karar verme son test $(\mathrm{z}=0.070, \mathrm{p}>0.05)$, beceri uygulama son test $(z=0.094, p>0.05)$, ayarlama son test $(z=0.223, p>0.05)$, kat1lım son test $(z=0.783, p>0.05)$, oyun performans1 son test $(\mathrm{z}=0.273, \mathrm{p}>0.05)$ ve varyansların homojen olduğu; karar verme ön test $(\mathrm{F}(1,28)=0.664, \mathrm{p}>0.05)$, beceri uygulama ön test $(F(1,28)=0.860, p>0.05)$, ayarlama ön test $(F(1,28)=0.856, p>0.05)$, kat1lım ön test $(F(1,28)=0.899, p>0.05)$, oyun performansı ön test $(F(1,28)=0.691, p>0.05)$, karar verme son test $(F(1,28)=0.901, p>0.05)$, beceri uygulama son test $(F(1,28)=0.822, p>0.05)$, ayarlama son test $(F(1,28)=0.759, p>0.05)$, kat1lim son test $(F(1,28)=0.819, p>0.05)$, oyun performansı son test $(\mathrm{F}(1,28)=0.928, \mathrm{p}>0.05)$ bulunmuştur. Bu sonuçlar doğrultusunda verileri analiz etmek için nonparametrik testlerin kullanılmasına karar verilmiştir. Gözlemcilerin oyun performansına ait bileşenlere verdikleri ön testson test puanları arasındaki tutarlılığın belirlenmesi amacıyla Mann Whitney U testi kullanılmıştır. Çalışma grubunun ön test ve son test puanları arasındaki gelişimi belirlemek için ise Wilcoxon işaretli sıralar testi kullanılmıştır. Araştırmada hata payı 0.05 olarak alınmıştır.

\section{BULGULAR}

Araştırma bulgularına göre, karar verme $(Z=-3.408, p<.001)$ (Tablo 6), beceri uygulama, $(Z=-3.408, p<.001)$ (Tablo 7), ayarlama, $(\mathrm{Z}=4.21, \mathrm{p}<.001)$ (Tablo 8) bileşenlerinde son testler lehine istatistiksel olarak anlamlı bir fark elde edilmiştir.

Tablo 6. Karar verme bileşeni ön-son test puanlarının karşılaştırılması

\begin{tabular}{llccccc}
\hline & Son-Ön Test & $\mathbf{n}$ & $\begin{array}{c}\text { Sıra } \\
\text { Ortalaması }\end{array}$ & $\begin{array}{c}\text { Sıra } \\
\text { Toplamı }\end{array}$ & $\mathbf{Z}$ & $\mathbf{p}$ \\
\hline Karar & Negatif Sıra & 0 & 0.00 & 0.00 & -3.408 & $0.001^{*}$ \\
verme & Pozitif Sıra & 15 & 8.00 & 120.00 & & \\
& Eşit & 0 & & & & \\
\hline
\end{tabular}

Tablo 7. Beceri uygulama bileşeni ön-son test puanlarının karşılaştırılması

\begin{tabular}{llccccc}
\hline & Son-Ön Test & $\mathbf{n}$ & $\begin{array}{c}\text { Sıra } \\
\text { Ortalaması }\end{array}$ & $\begin{array}{c}\text { Sıra } \\
\text { Toplamı }\end{array}$ & Z & p \\
\hline Beceri & Negatif Sıra & 0 & 0.00 & 0.00 & -3.408 & $0.001^{*}$ \\
Uygulama & Pozitif Sıra & 15 & 8.00 & 120.00 & & \\
& Eşit & 0 & & & & \\
\hline
\end{tabular}

Tablo 8. Ayarlama bileşeni ön-son test puanlarının karşılaştırılması

\begin{tabular}{llccccc}
\hline & $\begin{array}{l}\text { Son-Ön } \\
\text { Test }\end{array}$ & $\mathbf{n}$ & $\begin{array}{c}\text { Sıra } \\
\text { Ortalaması }\end{array}$ & $\begin{array}{c}\text { Sıra } \\
\text { Toplamı }\end{array}$ & $\mathbf{Z}$ & $\mathbf{p}$ \\
\hline Ayarlama & Negatif Sıra & 0 & 0.00 & 0.00 & -3.420 & $0.001^{*}$ \\
& Pozitif Sıra & 15 & 8.00 & 120.00 & & \\
& Eşit & 0 & & & & \\
& & & & & \\
\hline
\end{tabular}

Araştırmada sporcuların oyuna katılım $(Z=-3.413, \mathrm{p}<.001)$ (Tablo 9) ve oyun performanslarında $(Z=-4.408$, $\mathrm{p}<.001$ ) (Tablo 10) son testler lehine istatistiksel olarak anlamlı bir fark elde edilmiştir. 
Tablo 9. Oyuna katılım ön-son test puanlarının karşılaştırılması

\begin{tabular}{llccccc}
\hline & $\begin{array}{l}\text { Son-Ön } \\
\text { Test }\end{array}$ & $\mathbf{n}$ & $\begin{array}{c}\text { Sıra } \\
\text { Ortalaması }\end{array}$ & $\begin{array}{c}\text { Sıra } \\
\text { Toplamı }\end{array}$ & $\mathbf{Z}$ & $\mathbf{p}$ \\
\hline Oyuna & Negatif Sıra & 0 & 0.00 & 0.00 & -3.413 & $0.001^{*}$ \\
Katılım & Pozitif Sıra & 15 & 8.00 & 120.00 & & \\
& Eşit & 0 & & & & \\
\hline
\end{tabular}

Tablo 10. Oyun performansı ön-son test puanlarının karşılaştırılması

\begin{tabular}{llccccc}
\hline & Son-Ön Test & $\mathbf{n}$ & $\begin{array}{c}\text { Sıra } \\
\text { Ortalaması }\end{array}$ & $\begin{array}{c}\text { Sıra } \\
\text { Toplamı }\end{array}$ & $\mathbf{Z}$ & $\mathbf{p}$ \\
\hline Oyun & Negatif Sıra & 0 & 0.00 & 0.00 & -4.408 & $0.001^{*}$ \\
Performansı & Pozitif Sıra & 15 & 8.00 & 120.00 & & \\
& Eșit & 0 & & & & \\
\hline
\end{tabular}

Bu sonuçlar doğrultusunda sporcuların karar verme, beceri uygulama, ayarlama bileşenleri ve bu bileşenlere bağlı olarak ortaya çıkan oyuna katılım ve oyun performansında giriş davranışları ile çıkış davranışları arasında çıkış davranışları lehine istatistiksel olarak anlamlı bir artış olduğu söylenebilir

\section{TARTIŞMA}

Çalışmada karar verme bileşeninde hangi beceriyle servis karşılandı̆̆ı, karşılanan servis sonrasında topun hangi

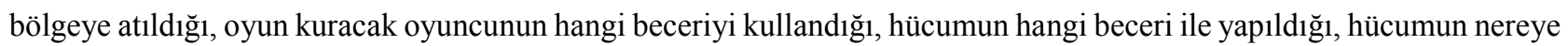
yapıldığı kriterleri dikkate alınmıştır. Araştırma sonuçları sporcuların ön test ve son testlerdeki karar verme indekslerinin, son testler lehine istatistiksel olarak anlamlı bir artış olduğunu göstermektedir. Çalışmanın bulguları farklı branşlarda yapılan çalışmalar ile paralellik göstermektedir (Alarcón ve diğerleri, 2009; Broek ve diğerleri, 2011; French ve diğerleri 1996; Gray ve Sproule 2011; Güneş, 2017; Harvey 2004; Mitchell ve diğerleri,1995; Şahin 2007; Turner, 1996; Turner ve Martinek,1999; Žuffová ve Zapletalová, 2015). Çalışmada sporcuların ön testteki karar verme indekslerini meydana getiren davranışlar analiz edildiğinde, servis karşılayacak oyuncuların genellikle manşet pası uygulama girişiminde oldukları, bununla birlikte oyunun gerektirdiği bazı durumlarda örneğin çok sert gelmeyen ancak üsten gelen bir servisi karşılamak için manşet pas kullanmada ısrar ettikleri görülmüştür. Bunun dışında oyunu kuracak oyuncunun (pasör) ve hücum vuruşu yapacak olan oyuncunun genellikle manşet pası tercih ettiği söylenebilir. Ön testlerde genellikle bir hücum girişimi ya pasöre uygun top atılamaması ile ya da üç manşet pas uygulaması ile sonuçlanmıştır. Bu süreç etkili bir hücumun oluşmasını engellemiştir. Aynı zamanda hücum vuruşu yapacak olan oyuncuların genellikle hücumu gerçekleştirirken sadece topu filenin karşı tarafına geçirmekle ilgilendiği görülmüştür. Son testlerde ise servis genellikle manşet pas ile karşılanmış, bu karşılama esnasında sporcuların manşet pas için topun durumuna göre gerekli yer değiştirme hareketleri (öne, geriye, yana hareket etme) yaptıkları gözlemlenmiş, manşetin genellikle oyun kurucuya doğru alınması sağlanmış ve oyun kurucunun uygun gelen toplar için (istenilen yükseklik ve hız) parmak pası tercih ettiği ve hücum vuruşu yapacak olan oyuncuya fileye paralel toplar attığı gözlenmiştir. Hücum vuruşu yapacak olan oyuncu ise etkili bir hücum için karşı sahadaki boşlukları dikkate alarak hücum yapmış ve hücumlarında ya sıçrayarak parmak pas ya da filenin üstünde aşağıya doğru giden toplar atarak hücumu tamamlamıştır. Bu sonuçlar taktik oyun yaklaşımının voleybolda oyun içerisinde karar verme bileşenini olumlu yönde geliştirdiğini göstermektedir.

Çalışma TOYA’ ya dayalı olarak yürütülen voleybol eğitiminin sporcuların beceri uygulama bileşenleri üzerinde son testler lehine istatistiksel olarak anlamlı bir fark oluşturduğunu göstermiştir. Çeşitli branşlarda yapılan çalışmalarda 
(Alison ve Thorpe,1997; Dinç, Altay ve Çelenk, 2008; French ve diğerleri, 1996; Harrison ve diğerleri, 2004; Harvey, 2003; Mitchell ve diğerleri, 1995; Şahin 2007; Turner ve Martinek,1999; Tuzcuoğlu,2006; Žuffová ve Zapletalová, 2015) beceri uygulamada benzer sonuçlar bulunmuştur. Çalışmada, beceri uygulama bileşeninde sporcuların parmak pas, manşet pas, servis ve hücum vuruşu becerileri ölçülmüştür. Oyuncu oyun kuralları doğrultusunda nizami yaptığı her beceride olumlu (etkili), topu taşıdığı, firlattığı, dışarı (out) attığı her pozisyonda olumsuz (etkili değil) puan almıştır. Yapılan çalışmada ön testlerde servisi karşılayacak oyuncular, servisi manşet pas ile karşılamışlar ancak genellikle oyun kurucunun istediği yükseklikte ve açıda bir karşılama sergileyememişlerdir. Sporcuların genel olarak parmak pas ve hücum vuruşu becerilerini çok fazla uygulayamadıkları gözlenememiştir. Ancak sporcuların son testlerde manşet pas, parmak pas ve hücum vuruşu becerilerini kombine şekilde uyguladıkları gözlenmiştir. Ön test ve son testlerdeki bu sürecin uygun karar verme bileşeninden de etkilendiği düşünülmektedir. Çünkü bir oyuncunun servisin hangi beceriyle karşılanacağına karar verip uygun beceriyi seçmesi, oyun kuracak oyuncunun beceri performansını ve dolayısıyla hücum yapacak olan oyuncunun da performansını etkilemiş olabilir. Mitchell ve diğerleri (2013:20) beceriyi yürütmenin kritik olduğunu ancak oyun durumunda ne yapacağına karar vermenin bir o kadar önemli olduğunu vurgulamaktadırlar. Sonuç olarak müdahale sonrasında sporcuların voleybol becerilerini uygulama performanslarında olumlu yönde bir değişiklik meydana gelmiştir.

Ayarlama bileşenindeki gelişimi ortaya koymak için araştırmaya katılan sporcuların ön test ve son testlerde sergilemiş oldukları topu takip etme, pasörün oyun kurma hazırlı̆̆ı ve hücum için yapılan hazırlıklar dikkate alınmıştır. Araştırma sonuçları TOYA' ya dayalı olarak yürütülen voleybol eğitiminin sporcuların ayarlama bileşenleri üzerinde son testler lehine istatistiksel olarak anlamlı bir yükselme olduğunu göstermektedir. Yapılan çalışmalarda ayarlama bileşeninin çok fazla incelenmediği görülmektedir. Harvey (2004)'in futbol branşında yaptığı çalışma ayarlama bileşeninde benzer sonuçları ortaya koymaktadır. Bununla birlikte bazı çalışmalarda oyunların taktiksel yapısının farklı olması nedeniyle oyun performansının destekleme bileşeni (pas almak ve şut atmak için topsuz oyuncunun uygun pozisyon alması) incelenmiş ve destekleme bileşeninin olumlu olarak geliştiği bulunmuştur (Alarcón ve diğerleri, 2009; Güneş, 2017; Şahin 2007). Bu çalışmada ön testte top sporcunun üzerine doğru geliyorsa manşet karşılanmış, ancak topun servisi karşılayacak oyuncunun biraz önüne, yanına veya arkasına geldiği durumlarda oyuncuların öne, geriye, yana hareket etmede sorunlar yaşadıkları ve topu çok iyi takip etmedikleri gözlenmiştir. Bununla birlikte pasör top üzerine geliyorsa manşet pas ile oyunu kurmuş, kendinden uzakta olan toplar için topa doğru yönelmemiş, hücum oyuncusunun tam üstüne doğru toplar atmıştır. Hücum oyunsu da üstüne gelen topları manşet pas ile karşı tarafa göndermeye çalışmıştır. Ancak son test verileri incelendiğinde, sporcuların ön teste göre topu daha iyi takip ettikleri, oyun kurucunun oyun kurmak için hazırlık yaptığı, topu hücum yapacak oyuncunun önüne fileye paralel olarak attığı, hücum yapacak oyuncunun ise hücum vuruşu için hazırlık yaptığı gözlenmiştir. Bu sonuçlar taktik oyun yaklaşımının voleybolda ayarlama bileşeninde olumlu değişiklikler meydana getirdiğini göstermektedir.

Çalışmada TOYA' ya dayalı olarak yürütülen voleybol eğitiminin sporcuların oyuna katılımı üzerinde son testler lehine anlamlı bir fark oluşturduğu da ortaya konmuştur. Araştırmada "oyuna katılım = uygun kararların sayısı + uygun olmayan kararların sayıs1 + etkin beceri uygulama sayıs1 + verimsiz beceri uygulama sayısı + uygun ayarlama hareketi sayısı" sonuçları üzerinden yapılan hesaplama ile elde edilmiştir (Oslin ve diğerleri, 1998). Sporcuların karar verme, beceri uygulama ve ayarlama bileșenlerindeki olumlu performansları sporcuların daha fazla oyuna katılmasında etkili olmuştur. Ayrıca sporcuların uygun kararlar vermesi ve ayarlamalar yapması, uygun olmayan karar vermede bir azalmaya ve dolaylı olarak da uygun beceri uygulama sayılarında artmaya neden olmuş olabilir. Bu sonuç araştırma için olumlu bir bulgudur. Çünkü oyuna katılım daha sonraki gelişmeler için ön koşuldur. Yani sporcuların oyunlarda 
becerilerini ilerletmek için daha fazla deneyime sahip olmalarını demektir. Yapılan farklı branşlardaki çalışmalarda da benzer sonuçlar elde edilmiştir (Harvey, 2004; Mitchell, Oslin ve Griffin, 1995).

Oyun performansı incelendiğinde ise TOYA' ya dayalı olarak yürütülen voleybol eğitiminin sporcuların oyun performansı üzerinde de anlamlı etki oluşturduğu bulunmuştur. Tıpkı oyuna katılımın hesaplanmasında olduğu gibi "oyun performansı = (karar verme indeksi + beceri uygulama indeksi + ayarlama indeksi) / 3" formülü üzerinden yapılan bir hesaplama ile elde edilmiştir (Oslin ve diğerleri, 1998). Araştırmaya katılan sporcuların bireysel olarak karar verme, beceri uygulama ve ayarlama indekslerindeki artış, sporcuların her birinin oyun performanslarının olumlu yönde değişmesine neden olmuştur. Farklı sportif oyunların öğretimi ile ilgili yapılan çalışmalarda benzer sonuçlar raporlanmıştır (Bohler, 2009; Güneş, 2017; Lee ve Ward 2009; Şahin 2007; Tuzcuoğlu, 2006).

Yapılan çalışmanın bulguları genel olarak değerlendirildiğinde taktik oyun yaklaşımının voleybol oyun performansını olumlu yönde geliştirdiği görülmektedir. Oyun performansını geliştirmek bir başka ifade ile sporculara oyunun gerektirdiği taktikleri öğretmek, uygun öğrenme ortamları oluşturularak sağlanabilir. Taktik oyun yaklaşımı bu ortamı sağlamada etkili olmuştur. Henninger ve diğerleri (2006) voleybol branşında yaptıkları çalışmada öğrencilerin var olan bilgileri ile taktiksel bir anlayış geliştirmelerinin zor olduğunu, taktikleri geliştirmek için öğretmenler tarafından uygun ortamlar sağlamanın gerekli olduğunu söylemektedirler. Yapılan bu çalışmada taktikleri öğretmek için istenilen bir ortam içerisinde uygun bir öğretim modeli kullanılmış ve sonuç olarak sporcuların oyun performansında niceliksel olarak bir artış meydana gelmiştir. Ayrıca Bohler (2009)'in voleybol branşında nitel olarak öğrenci ve öğretmenler ile yaptığı çalışma TOYA'nın taktiksel bilgiyi geliştirebileceği ile ilgili ipuçları da araştırma bulgularını desteklemektedir. Bunun yanında Harrison ve diğerleri (2004)'nin üniversite öğrencileri üzerinde yaptıkları çalışma voleybol oynamada iyileşme, Broek (2011)'un üniversite öğrencileri üzerinde yaptıkları çalışma ise voleybol taktiksel farkındalığında artış olduğunu göstermektedir. Çalışmada elde edilen bulgular Harrison ve diğerleri (2004) ve Broek (2011)'in çalışmalarını desteklemek ile birlikte, küçük yaş gruplarında da yapılan çeşitli uyarlamalar ile oyun performansının geliştirilebileceğini de ortaya koymaktadır.

\section{SONUÇ VE ÖNERILER}

Sonuç olarak, TOYA'nın voleybola yeni başlayanların çalışmalarında oyuna ait taktiksel özelliklerin geliştirilmesi için etkin bir öğretim modeli olduğu söylenebilir. TOYA ile sporcuların oyuna katılımları artacak ve süreç içerisinde her oyuncunun oyunu daha fazla deneyimle şansı olacaktır. Ancak gerçekleştirilen çalışmanın bazı sınırlılıkları da bulunmaktadır. Bunlardan birisi, çalışmada kontrol grubunun kullanılamamasıdır. Çalışmanın yapıldığı alt yapı kulübünde çalışma sırasında yeterince sporcu bulunmaması böyle bir sınırlılığa neden olmuştur. Bununla birlikte çalışma sadece sınırlı sayıda kız sporcular üzerinde yürütülmüştür. Benzer çalışmaların kontrol grubu ile desenlenerek, farklı branşların taktiksel yapılarını geliştirmedeki etkisini de ortaya koyacak şekilde, her iki cinsten sporcuyu kapsayan ve daha fazla katılımcı sayısı ile tekrarlanması, konu ile ilgili daha güvenilir sonuçların alınmasına katkı getirecektir.

\section{KAYNAKLAR}

1. Alarcón, F.,Cardenas, D., Miranda, M. T., Urena, N., Pinar, M. I., Torre, E. (2009). Effect of a training program on the improvement of basketball players' decision making. Revista de Psicología del Deporte, 18(3), 403-407.

2. Alison, S., Thorpe, R. (1997) Comparison of the effectiveness of two approaches to teaching games within PE. A skills approach verses a games for understanding approach. British Journal of Physical Education, 28(3): 9-13. 
3. Almond, L. (2015). Rethinking teaching games for undestanding. Agora For Pe and Sport, 17 (1) enero - april, 15-25

4. Bohler, H. (2009). Sixth-gradestudents, tactical understanding and decision making in a TGM volleyball unit. In: Hopper T, Butler J andStory B (eds) TGfU . . . simple good pedagogy: understanding a complexchallenge. Canada: Physical and Heath Education, 87-99.

5. Broek, G.,Boen, F., Claessens, M., Feys, J., Ceux, T. (2011). Comparison of three instructional approaches to enhance tactical knowledge in volleyball among university students. Journal of Teaching in Physical Education, 30(4), 375-392.

6. Bunker, D.,Thorpe, R. (1982). A model for the teaching of games in the secondary school. Bulletin of Physical Education, 10 , 9-16.

7. Cruz, A. (2004). Teachers' andstudents' perception of teaching game for understanding approach in physical education lessons. Journal of Physical Education and Recreation, 10(2): 57-66.

8. Çelen, A. (2012). Spor Eğitimi Modeli İle İşlenen Voleybol Derslerinin Öğrencilerin Bilişsel, Duyuşsal Ve Psikomotor Erişi düzeylerine Etkisi. Yayımlanmamış Doktora Tezi. Gazi Üniversitesi. Eğitim Bilimleri Ensttitüsü.

9. Dinç, G., Altay, F. ve Çelenk, B. (2008). Voleybol oyununun öğretiminde taktik oyun yaklaşımının erişiye etkisi. 10. Uluslararası Spor Bilimleri Kongresi Bildiri. Kitapçı̆̆ı, 226-229.

10. French K.E.,Werner P.H., Rink, J.E. (1996). The effects of a 3-week unit of tactical, skill, or combined tactical and skill instruction on badminton performance of ninth-gradestudents. Journal of Teaching in Physica lEducation, 15: 418-438.

11. Gray, S.,Sproule, J. (2011). Developing pupils' performance in team invasion games. Physical Education and Sport Pedagogy, 16(1): 1532

12. Güneş, B. (2017). Basektbol Ünitesinde Taktik Oyun Yaklaşımının Lise Öğrencilerinin Bilişsel, Duyuşsal ve Psikomotor Erişi Düzeylerine Etkisi. Gazi Üniversitesi Sağlık Bilimleri Enstitüsü.

13. Harrison, J. M.,Blakemore, C. L., Richards, R. P., Oliver, J., Wilkinson, C., \& Fellingham, G. (2004). The effects of two instructional models-tactical and skill teaching-on skill development \& game play, knowledge, self-efficacy, \&student perceptions in volleyball. Physical Educator, 61(4), 186.

14. Harvey, S. (2004). Teaching games for understanding: a study of U19 college soccer players improvement in game performance using the game performance assessment instrument Australia:University of Melbourne, retrieved from https://www.researchgate.net/publication/237772609

15. Henninger, M. L.,Pagnano, K., Patton, K., Griffin, L. L., Dodds, P. (2006). Novice volleyball players' knowledge of games, strategies, tactics, and decision-making in the context of game play. New Zealand Physical Educator, 39(1), 34.

16. Holt, N. L.,Strean, W. B., Bengoechea, E. G. (2002). Expanding the teaching games for understanding model: new avenues for future research and practice. Journal of teaching in Physical Education, 21, 162-176.

17. Holt, J.,Ward, P., Wallhead, T. (2006). The transfer of learning from play practices to game play in young adult soccer players. Physical Education and Sport Pedagogy, 11(2): 101-118.

18. Hopper,T. (2003). Four Rs for tactical awareness: Applying game performance assessment in net/wall games. Teaching Noktaary Physical Education, 14(2), 16-21.

19. Jones, C.,Farrow, D. (1999). The transfer of strategic knowledge: A test of the games classification model. Bulletin of Physical Education, 9: $41-45$.

20. Lee, M.A.,Ward, P. (2009). Generalization of tactics in tag rugby from practice to games in middle school physical education. Physical Education and Sport Pedagogy, 14(2): 189-207.

21. Light, R. (2005). Making sense of chaos: Australian coaches talk about game sense. Teaching games for understanding: Theory, Research and Practice, 169-182.

22. Martin, R. (2004). An investigation of tactical transfer in invasion/territorial games. Research Quarterly for Exercise and Sport, 75 (1: March Supplement): A73-A74.

23. Metzler, M. W. (2005). Instructional Models for Physical Education. Second Edition.United States of America: Holcomb Hathaway, Inc.

24. Mitchell, S., Oslin, J. (1999). An investigation of tactical transfer in net games. European Journal of Physical Education, 4: 162-172.

25. Mitchell, S., Oslin, J.,Griffin, L. (1995). An analysis of two instructional approaches to teaching games. Research Quarterly for Exercise and Sport 66 (1: March Supplement): A65-A66.

26. Mitchell, S. A., Oslin, J. L., Griffin, L. L. (2013). Teaching Sport Concepts and Skills: A Tactical Games Approach for Ages 7 to 18. Human Kinetics, 19,20

27. Orkunoğlu, O. (1988). Voleybolda Takım Gelişimi ve Taktik. 1.Baskı. Ankara: Neyir Ofset

28. Oslin, J. L., Mitchell, S. A.,Griffin, L. L. (1998). The game performance assessment instrument (GPAI): development and preliminary validation. Journal of Teaching in Physical Education, 17, 231-243.

29. Pigott, B. (1982). A psychological basis for new trends in games teaching. Bulletin of Physical Education, 18(1), 17-22.

30. Pritchard, T., Hawkins, A., Wiegand, R., \&Metzler, J. N. (2008). Effects of two instructional approaches on skill development, knowledge, and game performance. Measurement in Physical Education and Exercise Science, 12(4), 219-236. 
31. Stolz, S., Pill, S. (2014). Teaching games and sport for understanding: Exploring and reconsidering its relevance in physical education. European Physical Education Review, 20(1), 36-71.

32. Şahin, R. (2007). Hentbolun Öğretiminde Taktik Oyun Yaklaşımının Etkisi. Yayımlanmamış Doktora Tezi. Hacettepe Üniversitesi.

33. Turner, A. (1996). Teachers' perceptions of technical and tactical models of instruction. Research Quarterly for Exercise and Sport, 67(Suppl), A-90

34. Turner, A., Martinek, T. (1999). An investigation into teaching games for understanding: Effects on skill, knowledge and game play. Research Quarterly for Exercise and Sport, 70(3):286-296.

35. Tuzcuoğlu, S. (2006). Taktik Oyun Yaklaşımının Tenis Öğretimi Üzerine Etkisi. Yayımlanmamış Yüksek Lisans Tezi. Abant İzzet Baysal Üniversitesi.

36. Wallhead, T., Deglan D. (2004). Effect of a tactical games approach on student motivation in physical education. Research Quarterly for Exercise and Sport, 75(1: MarchSupplement): A83-A84.

37. Žuffová, Z., Zapletalová, L. (2015). Efficiency of different teaching models in teaching of frisbee ultimate. Acta Facultatis Educationis Physicae Universitatis Comenianae, 55 (1), 64-73. 